\title{
PENGARUH BUDAYA ORGANISASI, LINGKUNGAN KERJA DAN KOMPETENSI TERHADAP KINERJA PEGAWAI DINAS PERTANIAN DAN PERKEBUNAN KABUPATEN BIMA
}

\author{
Fauzi M. Nur ${ }^{1}$, Siti Nurmayanti ${ }^{2}$, Sri Tatminingsih ${ }^{3}$ \\ 1Universitas Terbuka. E-mail: fauzitani@gmail.com
}

\section{ARTICLE INFO}

Keywords :

organizational culture, working environment, competence, and performance

Kata Kunci :

budaya organisasi, lingkungan kerja, kompetensi dan kinerja

\section{How to cite :}

M. Nur, Fauzi., Nurmayanti, Siti., Tatminingsih, Sri., (2020). Pengaruh Budaya Organisasi, Lingkungan Kerja dan Kompetensi Terhadap Kkinerja Pegawai Dinas Pertanian Dan Perkebunan Kabupaten Bima . 9 (4), JMM UNRAM, 353-368

DOI :

http://dx.doi.org/10.29303/imm.v9i4.582

Dikumpulkan : 24 September 2020

Direvisi :06 November 2020

Dipublikasi : 03 Desember 2020

\section{ABSTRACT}

This research is aimed to find out a partial and/or simultaneous influence of organizational culture, working environment, and competence of employees toward their working performance. The method used is a descriptive quantitative method using a questionnaire technique. Data were gained and collected since June to September 2019 by questionnaires distributed to 119 civil servants working in Agriculture and Plantation Services of Bima Regency. Furthermore, data were analyzed and processed using SPSSver.22 data processing tool for windows. Results of the analysis then interpreted and narrated descriptively. The results indicated that organizational culture (X1), working environment (X2), and competence (X3) as partially effect very much employees working performance $(Y)$ in Agriculture and Plantation Services of Bima Regency. It shows the value of the t-test results for each variable, namely X1: 4.779> t table 1.98; X2: 3,327> t table 1,98; and X3: 6,207> table 1.98 .

Tujuan dari penelitian ini adalah mengetahui ada tidaknya pengaruh budaya organisasi, lingkungan kerja, dan kompetensi secara parsial dan simultan terhadap kinerja pegawai. Metode yang digunakan adalah metode penelitian kuantitatif deskriptif dengan menggunakan teknik angket. Data dikumpulkan antara bulan Juni sampai September tahun 2019 dengan menyebarkan kuisioner kepada 119 pegawai negeri sipil yang bekerja di Dinas Pertanian dan Perkebunan Kabupaten Bima. Data yang terkumpul dianalisis menggunakan analisis statistik regresi linear berganda. Selanjutnya data diolah menggunakan perangkat olah data SPSSver.22 for windows. Hasil analisis data kemudian diinterprestasikan dan dinarasikan. 


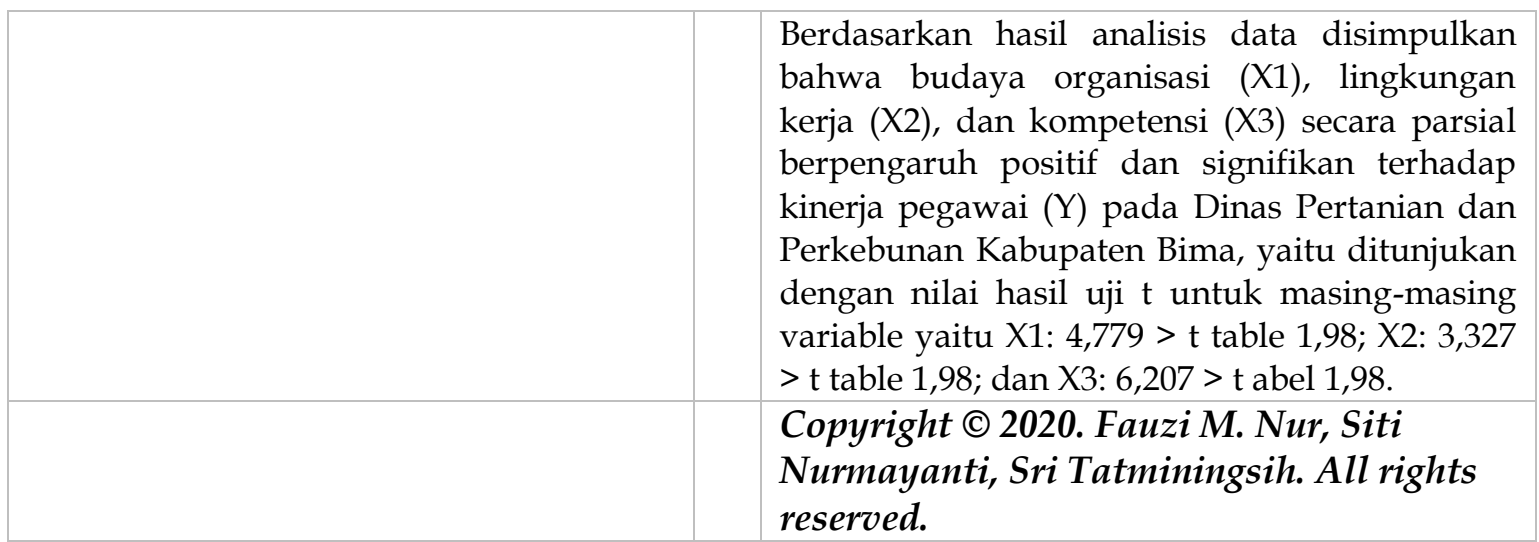

\section{PENDAHULUAN}

Bagi sebuah organisasi, sumber daya manusia (SDM) merupakan aset yang sangat berharga karena SDM memiliki potensi dalam dirinya yang menjadi kekuatan sehingga menjadi modal dasar bagi organisasi untuk mencapai tujuannya (Sunyoto, 2016). Dibutuhkan SDM yang berkualitas dalam bidang pekerjaan agar tujuan organisasi dapat tercapai seperti profesionalisme, memiliki kompetensi yang tinggi, komitmen terhadap organisasi, ulet dan telaten dalam bekerja sehingga organisasi dapat disebut memiliki kinerja baik (Sobirin, 2015).

Pencapaian kinerja yang baik sebagai akibat dari peningkatan produktivitas dapat terjadi melalui penguatan budaya organisasi (Rismayadi \& Maemunah, 2016). Budaya organisasi adalah suatu upaya yang diciptakan dan dikembangkan oleh sekelompok anggota organisasi dalam memecahkan masalah eksternal dan internal berdasarkan pola asumsi dasar berupa nilai-nilai, norma dan kepercayaan yang dianut (Robins, 2014). Pendapat berbeda dikemukakan oleh (Trisnaningsih, 2007), bahwa kinerja karyawan tidak memiliki korelasi dengan budaya organisasi.

Kinerja juga dapat dipengaruhi oleh lingkungan kerja. Segala sesuatu yang ada disekitar para pekerja seperti lokasi geografis kantor, kualitas udara, tingkat kebisingan, kesejahteraan karyawan, dan keamanan serta kenyamanan didefinisikan sebagai lingkungan kerja (Clayton, 2003). Peningkatan produktivitas dapat dicapai melalui penciptaan kondisi lingkungan kerja yang nyaman bagi karyawan, sebaliknya kondisi lingkungan kerja yang tidak nyaman berpotensi terjadinya stress kerja yang dapat menurunkan kinerja (Jayaweera, 2015). Hasil penelitian yang berbeda dilakukan terhadap karyawan bagian sortir PT.Tiki Sukoharjo dimana dengan kondisi fasilitas kerja yang kurang memadai, karyawan tetap menunjukan kinerja yang baik. Hal ini disebabkan karena desakan kebutuhan hidup yang memaksa mereka untuk bekerja maksimal meski lingkungan kerja kurang mendukung (Widodo \& Wariati, 2016).

Selanjutnya kompetensi menjadi salah satu faktor yang banyak menjadi perhatian para peneliti sosial terkait dengan hubungannya dengan kinerja karyawan. (Yaşar et al., 2013) menyebutkan bahwa kinerja organisasi dapat ditingkatkan melalui peningkatan kompetensi karyawan. Kompetensi adalah karakteristik yang mendasar pada seseorang yang mempengaruhi kinerja (Simanjuntak, 2011) atau kemampuan dasar yang dimiliki seseorang untuk melakukan suatu pekerjaan (Robins, 2014). Pendapat berbeda dikemukakan oleh (Dhermawan et al., 2012) bahwa kompetensi tidak berpengaruh terhadap kinerja pegawai Dinas PU Provinsi Bali. Hal ini disebabkan karena pegawai lebih menghendaki kompensasi yang lebih tinggi daripada kompetensi untuk menunjang pencapaian kinerja yang lebih baik. 
Berdasarkan pengamatan penulis, terdapat fenomena pada kantor pusat Distanbun kabupaten Bima, yaitu tingkat kehadiran pegawai yang ditunjukan dengan partisipasi apel pagi dan sore yang berbeda. Hal ini dapat ditunjukkan dengan bukti absensi kehadiran apel pagi dan sore hari terhadap 119 orang pegawai selama 4 bulan terakhir yaitu Februari, Maret, April dan Mei 2019 dimana dalam empat bulan partisipasi pegawai dalam apel pagi hanya sampai $84,44 \%$ dan pada apel sore tingkat partisipasinya hanya $48,50 \%$. Keadaan tersebut menunjukan rendahnya budaya organisasi pada kantor pusat Distanbun kabupaten Bima. Hasil wawancara awal penulis dengan beberapa pegawai tentang sebab mereka tidak hadir pada kegiatan apel sore adalah karena merasa malas dan merasa sudah menandatangani absensi kehadiran pada saat apel pagi.

Fenomena lainnya yang penulis temukan adalah kondisi lingkungan kerja dalam dimensi fisik seperti seringnya mati listrik karena daya listrik tidak cukup untuk menyuplai kebutuhan setiap ruangan sehingga $\mathrm{AC}$, kipas angin, dan perangkat elektronik lainnya ikut mati yang menyebabkan suasana ruangan panas dan pengap, disamping itu adanya aktivitas keluar masuk tamu, LSM dan seringnya demontrasi oleh sebagian masyarakat menyebabkan suara bising yang dirasakan sangat mengganggu bagi aktivitas kerja para pegawai. Keadaan ini sesuai dengan hasil wawancara penulis dengan hampir semua pegawai yang menyatakan bahwa mereka merasa risih dan tidak nyaman dengan adanya aktivitas demonstrasi dan keluar masuk tamu yang sering tidak menunjukan sikap sopan santun. Sedangkan lingkungan kerja dalam dimensi non fisik berkaitan dengan hubungan kerja antara sesama rekan kerja ataupun dengan atasan yang seringkali tidak begitu koperatif dimana ketika penulis melakukan wawancara dengan beberapa pegawai, ada pegawai yang merasa tidak nyaman dengan sikap rekannya dan ada juga yang merasa tidak puas dan bahkan tidak suka dengan pimpinannya. Keadaan ini tentu saja tidak baik bagi kelangsungan organisasi.

Aspek lain yang diamati oleh penulis adalah aspek pengetahuan, keterampilan, dan kapabilitas pegawai atau yang disebut kompetensi pegawai. Dari hasil diskusi dan wawancara awal penulis dengan beberapa pegawai didapatkan informasi bahwa sebagian pegawai merasa jabatan atau tugas kewenangan yang diberikan kepadanya kurang sesuai dengan basis ilmu yang dimilikinya sehingga merasa kurang mampu melaksanakan tugas dan tanggung jawab tersebut. Dan faktanya dari 21 jabatan struktural di kantor di Distanbun kabupaten Bima terdapat 8 jabatan yang bukan berasal dari sarjana pertanian.

Berdasarkan fenomena tersebut, maka menjadi alasan utama penulis untuk melakukan penelitian dengan judul "Pengaruh Budaya Organisasi, Lingkungan Kerja dan Kompetensi Terhadap Kinerja Pegawai Dinas Pertanian dan Perkebunan Kabupaten Bima".

Adapun tujuan penelitian adalah untuk mengetahui ada atau tidak ada pengaruh budaya organisasi terhadap kinerja pegawai, mengetahui ada atau tidak ada pengaruh lingkungan kerja terhadap kinerja pegawai, dan mengetahui ada atau tidak ada pengaruh kompetensi terhadap kinerja pegawai.

\section{TINJAUAN PUSTAKA}

\subsection{Penelitian Terdahulu}

Beberapa penelitian yang relevan dengan penelitian in telah dikumpulkan oleh peneliti, diantaranya penelitian yang dilakukan oleh Faizal dan Ugheoke (2016), yang meneliti tentang pengaruh budaya organisasi terhadap kinerja pegawai pemerintah di Oman yang menyimpulkan bahwa budaya organisasi berpengaruh positif dan signifikan 
terhadap kinerja pegawai pemerintah Oman. Demikian juga dengan penelitian yang dilakukan oleh Alicia Lorraine Dorai Ponnu and Zubair Hassan (2015), yang berjudul pengaruh budaya organisasi terhadap manajemen kinerja menyimpulkan adanya korelasi positif dan signifikan antara organisasi dengan manajemen kinerja.

Selanjutnya penelitian tentang pengaruh lingkungan kerja terhadap kinerja dilakukan oleh Nderi dan Kirai (2017), yang menyimpulkan adanya peningkatan kinerja karyawan melalui penciptaan lingkungan kerja yang kondusif. Hal ini juga didukung oleh penelitian Khaled dan Haneen (2017), yang menyebutkan bahwa lingkungan kerja yang aman dan nyaman dapat berpengaruh terhadap kinerja.

Penelitian tentang pengaruh kompetensi terhadap kinerja karyawan dilakukan oleh Murgianto dan Sulasmi (2016), yang menyebutkan adanya pengaruh positif dan signifikan terhadap produktivitas kerja pegawai kantor pelayanan terpadu Provinsi Jawa Timur. Demikian juga dengan penelitian yang dilakukan oleh Tristiana Rijanti, Bambang Suko Priyono, dan Heri Prasetiyo Nugroho (2017) yang menyimpulkan bahwa kompetensi berpengaruh positif dan signifikan terhadap kinerja pegawai badan keuangan daerah kota tegal.

\subsection{Tinjauan Teori}

2.2.1. Kinerja

Kinerja adalah suatu kegiatan yang dilakukan oleh seseorang dan menyempurakannya sesuai dengan tanggungjawabnya guna mendapatkan hasil sebagaimana telah ditetapkan (Pasolong, 2014). Menurut (Mangkunegara, 2014), (Sedarmayanti, 2016) dan (Wibowo, 2011) pengertian kinerja adalah hasil kerja (output) yang dicapai seorang karyawan berdasarkan tanggung jawab yang diberikan kepadanya baik secara kuantitas maupun kualitas. Sedangkan menurut Lebans dan Euske (2006) dalam (Taouab \& Issor, 2019). Kinerja merupakan tingkat pencapaian hasil yang diukur dengan indikator finansial dan atau bukan finansial.

Menurut (Sonnentag \& Frese, 2005) kinerja diartikan sebagai perilaku terukur individu yang relevan untuk tujuan organisasi yaitu pencapaian kriteria berupa efektivitas, efisiensi, dan produktivitas.

\subsubsection{Budaya Organisasi}

Budaya Organisasi dapat didefinisikan sebagai ciri khas yang dimiliki organisasi yang menjadi acuan bagi setiap anggota untuk melaksanakan tugas-tugas keorganisasian (Haryono, 2013). (Idowu, 2016) mendefinisikan istilah budaya organisasi ke dalam dua elemen penting yaitu stabilitas struktural dan integrasi. Elemen pertama, yaitu stabilitas struktural mengacu pada sekumpulan nilai-nilai yang dipegang teguh oleh anggota organisasi yang membedakannya dengan organisasi lain sehingga menjadi identitas organisasi. Elemen kedua, yaitu integrasi sebagai segudang pola perilaku, ritual, iklim, dan nilai-nilai yang bergabung untuk membentuk identitas organisasi.

Budaya organisasi adalah efek kolektif dari kepercayaan, perilaku, dan norma yang berlaku umum bagi individu-individu dalam organisasai. Norma-norma itu tersebut mengatur bagaimana karyawan melayani pelanggan, bagaimana mereka dapat bekerja sama, bagaimana mereka termotivasi, bagaimana mereka berkomitmen, terinspirasi serta terlibat dalam keseluruhan misi perusahaan (Nawawi, 2013), selanjutnya budaya organisasi menjadi rujukan anggota sehingga membentuk perilaku dan sikap dalam bekerja (Kretner \& Kinichi, 2014). 


\subsubsection{Lingkungan Kerja}

Salah satu unsur penting yang mempengaruhi aktifitas kerja karyawan adalah lingkungan kerja. (Jain \& Kaur, 2014) mendefinisikan lingkungan kerja ke dalam tiga aspek meliputi (1) lingkungan kerja fisik meliputi keseluruhan aspek terkait dengan keselamatan kerja karyawan, kelengkapan kerja dan kesehatan karyawan. (2) lingkungan kerja psikososial meliputi serangkaian faktor pekerjaan yang terkait dengan interaksi antar orang-orang, pekerjaan dan organisasi. (3) kesejahteraan karyawan. Mendukung definisi tersebut (Ciocirlan, 2017) mendefinisikan lingkugan kerja sebagai keadaan yang mempengaruhi kerja karyawan meliputi tiga bentuk yang berbeda tetapi saling terkait yaitu lingkungan fisik, psikologis dan sosial.

Lokasi geografis kantor, kualitas udara, tingkat kebisingan, kesejahteraan karyawan, dan bahkan tempat parkir yang sangat mempengaruhi aktivitas kerja karyawan disebut sebagai lingkungan kerja fisik (Sinnappan, 2017). Lingkungan kerja fisik juga didefinisikan sebagai rangkaian sistem kerja, desain pekerjaan,dan kondisi kerja yang terdapat pada organisasi dan mempengaruhi produktivitas kerja karyawan (Jayaweera, 2015).

\subsubsection{Kompetensi}

Menurut (Limawandoyo \& Simanjutak, 2013) definisi kompetensi adalah karakteristik yang mendasar pada seseorang yang mempengaruhi kinerja. Dapat juga didefinisikan sebagai kemampuan dasar yang dimiliki seseorang meliputi keterampilan, pengetahuan, sikap, dan perilaku yang dibutuhkan untuk melaksanakan tugasnya (Kurniawan et al., 2018). Kompetensi adalah standar kemampuan kerja setiap individu mencakup aspek pengetahuan, keterampilan dan sikap kerja (Sulasmi;Suhermin, 2016).

Sesuai dengan obyek penelitian ini, maka setiap karakteristik dan kemampuan yang dimiliki oleh seorang aparatur sipil negara (ASN) berupa pengetahuan, keterampilan, sikap maupun prilaku yang diperlukan dalam pelaksanaan tugas agar ia mampu bekerja professional, efisien dan efektif disebut dengan kompetensi (Sudarmanto, 2009 : 87).

\subsection{Kerangka Konseptual Penelitian}

Berdasarkan kajian teori yang telah disebutkan di atas dan berdasarkan hasil-hasil penelitian terdahulu, maka dibuat karangka konseptual penelitian sebagai berikut.

Gambar 2.1. Kerangka Konseptual Penelitian

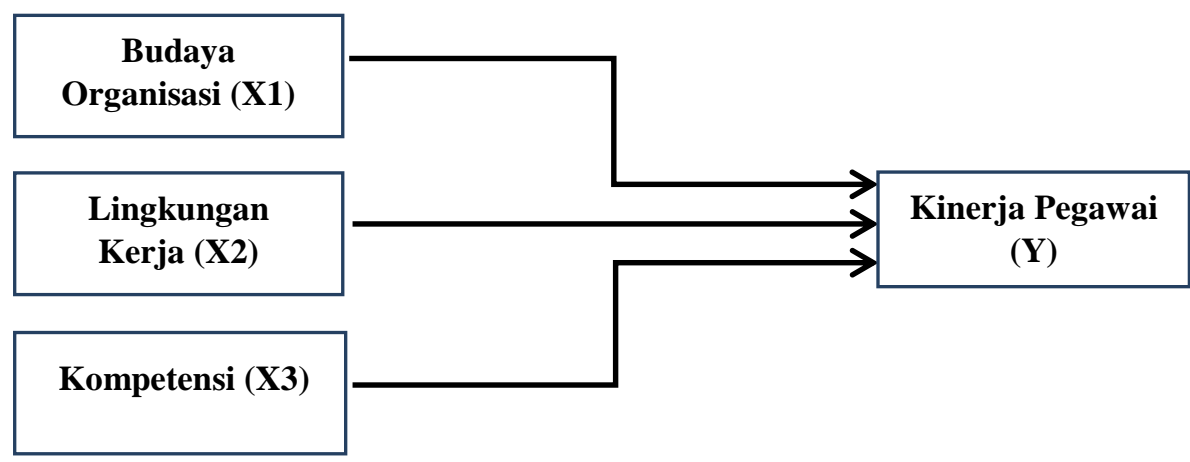

\subsection{Hipotesis Penelitian}

Berdasarkan kerangka penelitian di atas, maka peneliti menyusun hipotesis penelitian sebagai berikut :

H1 : Budaya organisasi berpengaruh positif dan signifikan terhadap kinerja pegawai. 
H2 : Lingkungan kerja berpengaruh positif dan signifikan terhadap kinerja pegawai $\mathrm{H} 3$ : Kompetensi berpengaruh positif dan signifikan terhadap kinerja pegawai.

\section{METODE PENELITIAN}

\subsection{Jenis Penelitian}

Penelitian ini menggunakan jenis penelitian asosiatif kausal, yaitu penelitian yang bertujuan untuk menganalisis pengaruh antar variabel atau lebih (Sugiyono, 2015).

\subsection{Teknik Pengumpulan Data}

Teknik pengumpulan data yaitu dengan cara observasi, wawancara, dan dokumentasi (Sugiyono, 2014).

\subsection{Populasi dan Sampel Penelitian}

Semua pegawai (populasi) yang bekerja pada kantor pusat Distanbun Bima yang berstatus ASN yaitu sebanyak 119 adalah orang yang ditetapkan sebagai responden dalam penelitian.

\subsection{Uji Instrumen Penelitian}

\subsubsection{Uji Validitas}

Cara menguji tingkat validitas data adalah dengan melakukan uji korelasi dengan menggunakan rumus di bawah ini (Bachri, 2010):

$$
\mathrm{r}_{\mathrm{xy}}=\frac{N \sum X Y-\left(\sum X\right)(y)}{\sqrt{\left.\left(\left(N \sum X^{2}\right)-\left(\sum X^{2}\right)\right]\left(N \sum Y^{2}\right)-\left(\sum Y^{2}\right)\right\}}}
$$

Semua parameter yang diuji menunjukan tingkat validitas yang tinggi.

\subsubsection{Uji reliabilitas}

Untuk menghitung tingkat reliabilitas instrumen menggunakan rumus sebagai berikut (Siregar, 2017).

$$
r_{11}=\left(\frac{k}{k-1}\right)\left(1-\frac{\sum \sigma_{b}^{n}}{\sigma_{t}^{n}}\right)
$$

Semua parameter yang diuji dalam penelitian ini dinilai konsisten.

\section{HASIL PENELITIAN DAN PEMBAHASAN}

\subsection{Deskripsi Karakteristik Responden}

Deskripsi karakteristik responden merupakan keberadaan responden yang terlibat dalam penelitian berdasarkan jenis kelamin, usia, masa kerja, dan tingkat pendidikan dari seluruh pegawai negeri yang bekerja di kantor pusat dinas pertanian dan perkebunan sejumlah 119 orang.

Adapun karakteristik responden dalam penelitian ini adalah sebagai berikut :

1. Mayoritas pegawai yang bekerja di kantor distanbun Bima adalah wanita sebanyak 72 orang atau $61 \%$

2. Mayoritas pegawai distanbun Bima berusia antara 41 - 50 tahun sebanyak 48 orang atau $41 \%$

3. Mayoritas pegawai memiliki masa kerja lebih dari 8 tahun atau $64 \%$ 
4. Mayoritas pegawai memiliki tingkat pendidikan tinggi (sarjana) sebanyak 102 orang atau $86 \%$

4.2. Hasil Analisis statistik deskriptif variable penelitian

\begin{tabular}{lclcl}
\hline No. & Simbol & $\begin{array}{l}\text { Variabel } \\
\text { penelitian }\end{array}$ & Mean & Kategori \\
\hline 1 & X1 & Budaya Organisasi & 3,95 & Kuat \\
2 & X2 & Lingkungan Kerja & 3,27 & Nyaman \\
3 & X3 & Kompetensi & 3,79 & Tinggi \\
4 & Y & Kinerja & 4,20 & Baik \\
\hline
\end{tabular}

Sumber : Data Primer Diolah (2019)

\subsection{Analisis statistik inferensial}

Hasil analisis regresi linier berganda diketahui persamaan regresi adalah sebagai berikut :

$$
Y=-0,790+0,465 X_{1}+0,291 X_{2}+0,580 X_{3}
$$

Keterangan :

Y : Kinerja

$\mathrm{X}_{1}$ : Budaya organisasi

$\mathrm{X}_{2}$ : Lingkungan kerja

$\mathrm{X}_{3}$ : Kompetensi

Persamaan regresi linier berganda di atas, menunjukkan nilai konstanta sebesar 0,790 yang menjelaskan apabila variabel budaya organisasi, lingkungan kerja, dan kompetensi bernilai 0 , maka variabel kinerja akan bernilai negatif sebesar $-0,790$.

\subsubsection{Uji asumsi klasik}

\begin{tabular}{|c|c|c|}
\hline Uji Asumsi Klasik & Hasil Uji & Kesimpulan \\
\hline Linearitas & $\begin{array}{l}\text { Nilai Linearity } 0,716 ; 0,10 ; \\
0,308\end{array}$ & $\begin{array}{l}\text { Terdapat hubungan } \\
\text { yang linear setiap } \\
\text { variable yang diuji }\end{array}$ \\
\hline Normalitas & Nilai Normalitas 0,398 & $\begin{array}{ll}\text { Data } & \text { berdistribusi } \\
\text { normal } & \end{array}$ \\
\hline Multikolinearitas & $\begin{array}{l}\text { Nilai VIF 2,163; 1,859; } \\
2,353\end{array}$ & $\begin{array}{l}\text { Tidak ada } \\
\text { mulitikolinearitas }\end{array}$ \\
\hline $\begin{array}{l}\text { Uji } \\
\text { Heterosk }\end{array}$ & $\begin{array}{l}\text { Nilai Sig. } 0,12 ; 0,91 ; 0,30> \\
0,05\end{array}$ & Tidak ada gejala \\
\hline
\end{tabular}

Sumber : Data Primer Diolah (2019) 


\subsubsection{Uji Regresi Linear Berganda}

Tabel 4.18 Koefisien Regresi

\begin{tabular}{|c|c|c|c|c|c|}
\hline \multirow[t]{2}{*}{ Model } & \multicolumn{2}{|c|}{$\begin{array}{l}\text { Unstandardized } \\
\text { Coefficients }\end{array}$} & \multirow{2}{*}{$\begin{array}{c}\text { Standardized } \\
\text { Coefficients } \\
\text { Beta } \\
\end{array}$} & \multirow[t]{2}{*}{$\mathbf{t}$} & \multirow[t]{2}{*}{ Sig. } \\
\hline & B & Std. Error & & & \\
\hline 1. (Constant) & $-0,790$ & 0,274 & & $-2,881$ & 0,005 \\
\hline $\begin{array}{l}\text { Budaya } \\
\text { Organisasi }\end{array}$ & 0,465 & 0,097 & 0,326 & 4,779 & 0,000 \\
\hline $\begin{array}{l}\text { Lingkungan } \\
\text { kerja }\end{array}$ & 0,291 & 0,087 & 0,210 & 3,327 & 0,001 \\
\hline $\begin{array}{l}\text { Kompetensi } \\
\text { Uii F }\end{array}$ & $\begin{array}{c}0,580 \\
116561\end{array}$ & 0,093 & 0,442 & 6,207 & $\begin{array}{l}0,000 \\
0,000\end{array}$ \\
\hline $\begin{array}{ll}\text { Adjust } & \mathbf{R} \\
\text { Squre } & \\
\end{array}$ & $\begin{array}{c}110,001 \\
0,290\end{array}$ & & & & 0,000 \\
\hline
\end{tabular}

\subsection{Pembahasan}

\subsubsection{Pengaruh budaya organisasi terhadap kinerja pegawai}

Berdasarkan hasil uji hipotesis (uji $t$ ) pengaruh variabel budaya organisasi terhadap variabel kinerja, menunjukan bahwa nilai t-hitung 4,779 lebih besar nilai t-tabel 1,98. Dengan demikian hipotesis yang menyatakan bahwa budaya organisasi berpengaruh positif dan signifikan terhadap kinerja pegawai dapat diterima. Hasil penelitian ini mendukung penelitian (Wahidah, 2019), (Faizal et al., 2019), (Andayani \& Soehari, 2019), (Ahidin \& Mutaqin, 2014), dan (Robins, 2014) yang menyatakan bahwa budaya organisasi berpengaruh positif dan signifikan terhadap kinerja pegawai.

Berdasarkan hasil pengamatan penulis dan wawancara terhadap beberapa pejabat pelaksana teknis kegiatan, mereka mengakui bahwa sering mengambil keputusan berani dalam kerja mereka meski mengandung risiko, seperti misalnya ketika ada upaya percepatan serapan anggaran, maka mereka berani mengambil keputusan yaitu mengubah mekanisme pencairan anggaran yang semula melalui mekanisme pengeluaran Kas Pembebanan Ganti Uang Persediaan (GU) kemudian diubah menjadi mekanisme Pengeluaran Kas Pembebanan Langsung (LS). Tentu saja kebijakan ini dilakukan setelah koordinasi dan laporan kepada atasan langsung. Akibatnya tingkat serapan anggaran pada kantor distanbun kabupaten Bima setiap tahun dinilai cukup baik yakni antara $80 \%$ sampai dengan $90 \%$.

Selanjutnya jumlah pegawai didominasi oleh pegawai dengan tingkat pendidikan sarjana (S1) 86\% dengan masa kerja lebih dari 8 tahun $64 \%$ sehingga mempengaruhi persepsi responden tentang kepercayaan diri dan tanggung jawab dalam melaksanakan pekerjaan sehingga berani mengambil resiko dan membuat keputusan untuk menyelesaikan masalah pekerjaan. Ini menunjukan kuatnya budaya organisasi pada kantor Distanbun Kabupaten Bima yang berdampak pada baiknya kinerja organisasi. Hal tersebut sejalan dengan hasil penelitian (Sagita et al., 2018), (Suwaryo et al., 2016), dan (Hakim, 2011) yang menyebutkan bahwa penerapan budaya organisasi yang baik seperti perilaku agresifitas pegawai dalam menyelesaikan tugas, inovatif dan berani mengambil resiko dapat meningkatkan kinerja organisasi. 


\subsubsection{Pengaruh Lingkungan Kerja terhadap Kinerja Pegawai}

Berdasarkan hasil uji hipotesis (uji t) pengaruh variabel lingkungan terhadap variabel kinerja, menunjukan bahwa nilai t-hitung 3,327 lebih besar nilai t-tabel 1,98. Dengan demikian hipotesis yang menyatakan bahwa lingkungan kerja berpengaruh positif dan signifikan terhadap kinerja pegawai dapat diterima. Hasil penelitian ini sesuai dengan penelitian (Suwondo \& Sutanto, 2015), (Hamdiyah et al., 2016), (Cintia \& Gilang, 2016), (Alvina, 2018), (Triastuti, 2019) dan (Suratman Hadi, 2019) yang menyebutkan bahwa lingkungan kerja fisik maupun non fisik dapat berpengaruh signifikan terhadap kinerja.

Berdasarkan hasil wawancara penulis dengan beberapa pegawai memberikan gambaran bahwa secara umum mereka merasa nyaman dengan kondisi gedung dan ruangan kantor karena dilengkapi dengan sarana kerja yang memadai seperti meja, kursi, computer dan penerangan, serta sirkulasi udara yang cukup meski masih terdapat sebagaian kecil ruangan yang kurang baik kondisinya. Selanjutnya pola kerja sama antara pegawai, desain tugas dan struktur pekerjaan yang terdapat di kantor distanbun kabupaten Bima cukup baik sehingga mereka merasa nyaman bekerja meski sebagai kecil pegawai merasa kurang baik hubungannya dengan pimpinan. Hal ini sesuai dengan penelitian (Sedarmayanti \& Rahadian, 2018), (Josephine \& Harjanti, 2017), (Indra Nugraha \& Surya, 2016) dan (Sidanti, 2015) yang menyatakan bahwa penciptaan kondisi lingkungan kerja yang nyaman melalui penciptaan tata letak kursi dan meja kerja, suhu dan aliran udara, pencahayaan yang memadai, hubungan kerja yang harmonis dan lain-lain dapat menyebabkan meningkatnya kinerja. Dapat diakui bahwa seringnya terjadi demontrasi dapat mengganggu aktivitas kerja pegawai sehingga mayoritas pegawai merasa tidak nyaman, tetapi tidak menurunkan semangat pegawai untuk menuntaskan tugas yang menjadi tanggungjawabnya.

Jika mengacu pada dekrispsi karakteristik responden, bahwa mayoritas pegawai berusia antara 41 sampai dengan 50 tahun atau $41 \%$. Ini menunjukan bahwa kantor Distanbun kabupaten bima memiliki SDM yang sangat matang dalam hal kebijakasanaan, cara berpikir dan mengambil keputusan, serta lebih tenang dalam menyikapi persoalan lingkungan sekitar pekerjaan mereka sehingga ketika terdapat persoalan seperti ruangan bocor, ada demonstrasi massa, dan lain-lain, mereka tetap fokus dengan pekerjaannya tanpa merasa terganggu dengan keadaan tersebut yang pada akhirnya berdampak pada baiknya kinerja organisasi. Hal ini sesuai dengan hasil penelitian (Mahendra, 2014) menyimpulkan bahwa semakin tinggi usia pekerja semakin baik kinerjanya karena lebih matang dalam bertindak.

\subsubsection{Pengaruh Kompetensi terhadap Kinerja}

Berdasarkan hasil uji hipotesis (uji t) pengaruh variabel kompetensi terhadap variabel kinerja, menunjukan bahwa nilai t-hitung 6,207 lebih besar nilai t-tabel 1,98. Dengan demikian hipotesis yang menyatakan bahwa kompetensi berpengaruh positif dan signifikan terhadap kinerja pegawai dapat diterima. Hasil penelitian ini sesuai dengan penelitian (Triastuti, 2019), (Posuma, 2013), (Subagyo et al., 2014), (Dedy Syahyuni, 2016), (Afrizoni, 2016), dan (Suryandita \& Netra, 2016) yang menyimpulkan bahwa kompetensi berpengaruh positif dan signifikan terhadap kinerja.

Hasil analisis menunjukan bahwa persepsi pegawai tentang kompetensi termasuk dalam kategori tinggi yang berpengaruh pada baiknya kinerja. Pegawai merasa bahwa mereka memiliki kompetensi yang tinggi untuk melaksanakan tugas yang diberikan yang dibuktikan dengan pemahaman yang baik tentang uraian tugas sehingga setiap perintah atasan dapat diselesaikan tepat waktu. Tingginya kompetensi pegawai menyebabkan baiknya kinerja organisasi, hal ini sesuai dengan penelitian (Rinawati \& Ingsih, 2015), 
(Callista, 2016), (Kurniawan et al., 2018), (Elizar \& Tanjung, 2018), dan (Noorita et al., 2019) yang menyatakan bahwa kompetensi pegawai yang tinggi dapat menyebabkan baiknya kinerja.

Selanjuatnya berdasarkan deskripsi karakteristik responden menunjukan bahwa pegawai dengan tingkat pendidikan tinggi (S1 dan D4) sangat dominan yakni sebanyak 102 orang atau $86 \%$. Dengan demikian dapat dipahami mengapa pegawai mempersepsikan bahwa mereka memiliki kompetensi tinggi untuk dapat melaksanakan pekerjaan yang menjadi tanggungjawabnya. Hal ini sesuai dengan hasil penelitian (Mamahit, 2013), (Wirotomo \& Pasaribu, 2015), dan (Nur, 2015) yang menyatakan bahwa makin tinggi tingkat pendidikan maka akan semakin mampu melaksanakan tugas yang menjadi tanggungjawabnya sehingga kinerja menjadi semakin baik.

\subsection{Implikasi Penelitian}

\subsubsection{Implikasi teoritis}

Implikasi teoritis berkaitan dengan sumbangan atau kontribusi pada perkembangan teori-teori dan ilmu pengetahuan tentang budaya organisasi, lingkungan kerja. dan kompetensi serta pengaruhnya terhadap kinerja. Hasil penelitian ini telah memberikan tambahan informasi dan pengetahuan terkait pengaruh yang sangat signifikan faktor budaya organisasi, lingkungan kerja, dan kompetensi terhadap kinerja pegawai khususnya di instansi pemerintah. Hal ini membuktikan hipotesis dan memperkuat teori maupun penelitian sebelumnya yang menjelaskan bahwa budaya organisasi, lingkungan kerja, dan kompetensi sangat berpengaruh pada kinerja pegawai.

Hasil penelitian ini membuktikan bahwa kinerja dipengaruhi oleh banyak faktor, dan beberapa diantaranya adalah budaya organisasi, lingkungan kerja, dan kompetensi. Sejalan dengan teori sebelumnya yang menyatakan bahwa kinerja dipengaruhi oleh berbagai faktor diantaranya menurut (Simanjuntak, 2011) adalah (1) sikap mental, motivasi kerja, etos kerja, pengetahuan, dan kondisi fisik pegawai; (2) lingkungan kerja yang terkait dengan keamanan, kesehatan, dan sarana kerja serta yang terkait dengan kesejahteraan atau upah; (3) regulasi dan kebijakan pemerintah yang terkait dengan manajemen industrial. Dan menurut (Latief et al., 2018) menyebutkan bahwa faktor yang mempengaruhi kinerja adalah (1) Faktor individu yaitu terkait dengan kemampuan, keterampilan, pengalaman kerja, tingkat sosial dan jenis kelamin; (2) faktor psikologi yaitu terkait dengan peran, sikap, persepsi, motivasi, kepriadian dan kepuasan kerja; (3) Faktor organisasi yaitu terkait dengan desain pekerjaan, kepemimpinan, dan sistem penghargaan serta jenjang karir.

\subsubsection{Implikasi praktis}

Implikasi praktis berkaitan dengan kuatnya budaya organisasi yang telah terbentuk pada diri pegawai, lingkungan kerja yang dirasakan nyaman, serta tingginya kompetensi yang dimiliki oleh pegawai pada kantor distanbun kabupaten Bima, telah mendorong baiknya kinerja pegawai dan organisasi. Unsur pimpinan seharusnya dapat mengelola keadaan ini dengan baik agar kinerja dinas dapat dipertahankan dan bahkan ditingkatkan. Budaya organisasi yang kuat ditambah lingkungan kerja yang nyaman serta kompetensi yang tinggi dapat memberikan konstribusi positif terhadap kinerja pegawai maupun organisasi.

Budaya organisasi terbukti berpengaruh terhadap kinerja pegawai pada kantor distanbun kabupaten Bima. Oleh karena itu unsur pimpinan harus memperhatikan dan menata dengan baik aspek budaya organisasi pada kantor distanbun kabupaten Bima, agar bisa berkontribusi positif pada peningkatan kinerja melalui penegakan disiplin dan 
konsistensi dalam melaksanakan aturan organisasi.

Lingkungan kerja juga terbukti berpengaruh terhadap kinerja, oleh karena itu unsur pimpinan harus mampu menjaga dan menata lingkungan kerja agar terus berkontribusi positif dalam mendorong kinerja lebih baik dengan cara menjaga keseimbangan lingkungan kerja ‘fisik dan lingkungan kerja non-fisik sehingga tercipta suasana kerja yang mendukung produktivitas dan kinerja organisasi.

Selanjutnya kompetensi terbukti berpengaruh terhadap kinerja pegawai. Oleh karena itu perlunya para pegawai pada kantor distanbun kabupaten Bima untuk terus meningkatkan kompetensinya khususnya pada pekerjaan yang bersifat administratif, penguasaan teknologi informasi, dan pemahaman kondisi lapangan, sehingga dengan kemampuan yang semakin tinggi tersebut akan semakin meningkatkan kinerja pegawai maupun organisasi.

\section{KESIMPULAN DAN SARAN}

\subsection{Kesimpulan}

Berdasarkan hasil analisis dan pembahasan maka dapat disimpulkan sebagai berikut:

1. Budaya organisasi berpengaruh positif dan signifikan terhadap kinerja pegawai pada kantor Dinas Pertanian dan Perkebunan Kabupaten Bima.

2. Lingkungan kerja berpegaruh positif dan signifikan terhadap kinerja pegawai pada kantor Dinas Pertanian dan Perkebunan Kabupaten Bima

3. Kompetensi berpengaruh yang positif dan sangat signifikan terhadap kinerja pegawai pada kantor Dinas Pertanian dan Perkebunan Kabupaten Bima

\subsection{Saran}

Berdasarkan hasil pembahasan dan kesimpulan di atas, maka dapat disarankan beberapa hal sebagai berikut :

1. Meskipun nilai rata-rata budaya organisasi termasuk pada kategori kuat dan berpengaruh pada baiknya kinerja pegawai, akan tetapi masih ada parameter budaya organisasi yang masih dalam kategori cukup kuat (sedang) yaitu paham terhadap masalah, sehingga untuk dapat lebih meningkatkan kepekaan pegawai dalam memahami permasalahan maka sebaiknya unsur pimpinan di kantor distanbun kabupaten Bima bisa lebih sering menyelenggarakan pelatihan-pelatihan serta lebih sering mengarahkan para pegawai agar meningkatkan kerja sama dan koordinasi.

2. Meskipun nilai rata-rata lingkungan kerja termasuk dalam kategori nyaman dan berpengaruh pada baiknya kinerja pegawai, akan tetapi potensi untuk meningkatkan kondisi lingkungan kerja menjadi sangat nyaman masih bisa dilakukan, mengingat masih ada parameter yang masuk dalam kategori tidak nyaman. Oleh karena itu sebaiknya unsur pimpinan melakukan penambahan fasilitas perlengkapan kerja, renovasi ruangan yang masih bocor, menambah daya listrik, memperbaiki sistem keamanan dengan menempatkan petugas keamanan (polisi pamong praja), serta percepatan relokasi kantor ke komplek pemda kab Bima agar membuat nyaman bekerja bagi para pegawai.

3. Meskipun kompetensi pegawai termasuk dalam kategori tinggi dan berpengaruh terhadap baiknya kinerja pegawai, akan tetapi untuk lebih meningkatkan kompetensi pegawai perlu diadakan pelatihan secara berkala dan perlunya penempatan pegawai sesuai dengan disiplin ilmu. 
4. Mengingat masih banyak faktor lain yang berpengaruh terhadap kinerja diantaranya adalah faktor motivasi, kompensasi, dan gaya kepemimpinan maka dapat menjadi aspek kajian bagi peneliti berikutnya untuk menguji sejauh mana pengaruh faktorfaktor lain tersebut terhadap kinerja dinas pertanian dan perkebunan kabupaten Bima. Selain itu jika kerangka pikir kajian sedikit direkayasa dengan memasukan salah satu variable bebas sebagai variable intervening, maka akan menjadi aspek yang menarik untuk dikaji oleh peneliti selanjutnya. 


\section{DAFTAR PUSTAKA}

Afrizoni, h. (2016). Analisis pengaruh kompensasi dan kompetensi terhadap peningkatan kinerja karyawan. Unes journal of social and economics research. Https:// doi.org/10.31933/ujser.1.2.067-083.2016

Ahidin, u., \& mutaqin, a. (2014). Hubungan antara budaya organisasi dan kinerja karyawan pada pt. Syaka putra transindo. Jurnal manajemen universitas pamulung, 1(2). Https://doi.org/10.1002/cjce.5450660615

Alvina, t. I. (2018). Analisis pengaruh lingkungan kerja dan budaya organisasi terhadap komitmen organisasional dengan kepuasan kerja sebagai variabel intervening. Diponegoro journal of management.

Andayani, a. A., \& soehari, t. D. (2019). Pengaruh budaya organisasi, komitmen organisasi dan gaya kepemimpinan terhadap kinerja karyawan. Akademika. Https://doi.org/10.34005/akademika.v8i02.366

Bachri, b. S. (2010). Meyakinkan validitas data melalui triangulasi pada penelitian kualitatif. Teknologi pendidikan.

Callista, n. (2016). Pengaruh kompetensi sdm terhadap kinerja karyawan pada pt.tresnamuda sejati cabang surabaya. Agora.

Cintia, e., \& gilang, a. (2016). Pengaruh lingkungan kerja fisik dan nonfisik terhadap kinerja karyawan pada kppn bandung i. Jurnal sosioteknologi. Https://doi.org/10.5614/sostek.itbj.2016.15.1.12

Ciocirlan, c. E. (2017). Environmental workplace behaviors: definition matters. Organization and environment. Https:// doi.org/10.1177/1086026615628036

Clayton, s. (2003). Environmental identity: a conceptual and an operational definition. In identity and the natural environment the psychological significance of nature.

Dedy syahyuni. (2016). Hubungan antara kompetensi dengan kinerja karyawan pada perusahaan jasa. Seminar nasional ilmu pengetahuan dan teknologi ko, 4(1), 27-34.

Dhermawan, a. A. N. B., sudibya, i. G. A., \& utama, i. W. M. (2012). Pengaruh motivasi, lingkungan kerja, kompetensi dan kompensasi terhadap kepuasan kerja dan kinerja pegawai. Jurnal manajemen, strategi bisnis, dan kewirausahaan.

Elizar, e., \& tanjung, h. (2018). Pengaruh pelatihan, kompetensi, lingkungan kerja terhadap kinerja pegawai. Jurnal ilmiah magister manajemen. Https://doi.org/10.30596/maneggio.v1i1.2239

Faizal, r., sulaeman, m., \& yulizar, i. (2019). Pengaruh budaya, motivasi kerja dan kompetensi terhadap kinerja karyawan. Eba journal: journal economics, bussines and accounting, 5(1), 11-21. Https://doi.org/10.32492/eba.v5i1.706

Hakim, 1. (2011). Membangun budaya organisasi unggul untuk keunggulan kompetitif. Benefit, $15(2)$ 106-123. Https://doi.org/https://doi.org/10.23917/ benefit.v15i2.1342

Hamdiyah, haryono, a. T., \& fathoni, a. (2016). Peningkatan kinerja karyawan melalui kompensasi, lingkungan kerja dan gaya kepemimpinan di swalayan banyumanik semarang. Journal of management.

Haryono, s. (2013). Teori budaya organisasi \& kepemimpinan. In prilaku organisasi.

Idowu, o. E. (2016). Understanding organisational culture and organisational performance: are they two sides of the same coin? Journal of management research, 8(4), 12. Https:// doi.org/10.5296/jmr.v9i1.10261

Indra nugraha, m., \& surya, i. (2016). Pengaruh kompensasi, lingkungan kerja dan promosi jabatan terhadap kepuasan kerja. E-jurnal manajemen universitas udayana.

Jain, r., \& kaur, s. (2014). Impact of work environment on job. International journal of scientific 
and research publications.

Jayaweera, t. (2015). Impact of work environmental factors on job performance, mediating role of work motivation: a study of hotel sector in england. International journal of business and management. Https://doi.org/10.5539/ijbm.v10n3p271

Josephine, a., \& harjanti, d. (2017). Pengaruh lingkungan kerja terhadap kinerja karyawan pada bagian produksi melalui motivasi kerja sebagai variabel intervening pada pt. Trio corporate plastic (tricopla). Jurnal agora.

Kretner \& kinichi. (2014). Organization behavior.

Kurniawan, d. A., guswandi, \& sodikin, a. (2018). The effect of competence and motivation on employee performance through employees capabilitieson pt. Binasinar amity. International journal of research science $\mathcal{E}$ management, 5(5), 48-60. Https://doi.org/10.5281/zenodo.1249804

Limawandoyo, e. A., \& simanjutak, a. (2013). Pengelolaan dan pengembangan sumber daya manusia pada pt. Aneka sejahtera engineering. Jurnal manajemen bisnis petra.

Mahendra, a. D. (2014). Analisis pengaruh pendidikan, upah, jenis kelamin, usia dan pengalaman kerja terhadap produktivitas tenaga kerja (studi di industri kecil tempe di kota semarang). Skripsi.

Mamahit, r. (2013). Tingkat pendidikan, pelatihan dan kepuasan kerja pengaruhnya terhadap kinerja pegawai di badan penanggulangan bencana provinsi sulawesi utara. Jurnal riset ekonomi, manajemen, bisnis dan akuntansi. Https://doi.org/10.35794/emba.v1i4.2830

Mangkunegara, d. (2014). Manajemen sumber daya manusia. International journal.

Nawawi. (2013). Budaya organisasi kepemimpinan dan kinerja. Nawawi (2013:244) yang berjudul budaya organisasi kepemimpinan dan kinerja.

Noorita, fathoni, a., \& minarsih, m. M. (2019). The effect of leadership style, competency, and organizational culture on employee performance with work environment as a mediation variable. Journal of management., 5(may), 1-12. Https://doi.org/10.19016/jcshokuriku.3.0_1

Nur, m. (2015). Pengaruh tingkat pendidikan, usia, dan peringkat penggajian (grading) terhadap kinerja pegawai kantor wilayah direktorat jenderal perbendaharaan provinsi kalimantan barat. Jurnal manajemen motivasi. Https://doi.org/10.29406/jmm.v10i2.31

Pasolong, h. (2014). Teori administrasi publik. Alfabeta.

Posuma, c. (2013). Kompetensi, kompensasi, dan kepemimpinan pengaruhnya terhadap kinerja karyawan pada rumah sakit ratumbuysang manado. Jurnal riset ekonomi, manajemen, bisnis dan akuntansi.

Rinawati, s. I., \& ingsih, k. (2015). Pengaruh linkungan kerja dan kompetensi terhadap kinerja karyawan dengan motivasi sebagai variabel intervening pada satuan kerja non vertikal tertentu (snot) kementrian pekerjaan umum di semarang.

Rismayadi, b., \& maemunah, m. (2016). Pengaruh motivasi kerja, kepemimpinan dan budaya organisasi terhadap kepuasan kerja karyawan serta dampaknya pada kinerja perusahaan (studi kasus pada pt. Concord indonesia). Jurnal manajemen $\mathcal{E}$ bisnis kreatif. Https://doi.org/10.36805/manajemen.v2i1.181

Robins, stephen. P. (2014). Teori budaya organisasi. In perilaku organisasi.

Sagita, a. A., susilo, h., \& cahyo, m. (2018). Pengaruh budaya organisasi terhadap kinerja karyawan dengan motivasi kerja sebagai variabel mediator (studi pada pt astra internasional, tbk-toyota (auto2000) cabang sutoyo malang). Jurnal administrasi bisnis (jab) | vol, 57(1).

Sedarmayanti. (2016). Manajemen sumber daya manusia. In manajemen sumber daya 
manusia.

Sedarmayanti, s., \& rahadian, n. (2018). Hubungan budaya kerja dan lingkungan kerja terhadap peningkatan kinerja pegawai pada lembaga pendidikan tinggi. Jurnal ilmu administrasi: media pengembangan ilmu dan praktek administrasi. Https://doi.org/10.31113/jia.v15i1.133

Sidanti, h. (2015). Pengaruh lingkungan kerja, disiplin kerja dan motivasi kerja terhadap kinerja pegawai negeri sipil di sekretariat dprd kabupaten madiun. Jurnal jibeka.

Simanjuntak, p. (2011). Manajemen dan evaluasi kinerja. In lembaga penerbit fakultas ekonomi universitas indonesia: jakarta.

Sinnappan, t. (2017). Working environment and its influence on employees' performance: a case study of an oil and gas vendor company in malaysia. Master thesis, universiti tunku abdul rahman.

Siregar, s. (2017). Statistika parametik untuk penelitian kuantitatif dilengkapi dengan perhitungan manual dan aplikasi spss versi 17. In statistika parametik untuk penelitian kuantitatif dilengkapi dengan perhitungan manual dan aplikasi spss versi 17.

Sobirin, a. (2015). Organisasi dan perilaku organisasi. Budaya organisasi, pengertian, makna dan aplikasinya. Https:/ / doi.org/10.1080/09853111.2000.11105363

Sonnentag, s., \& frese, m. (2005). Performance concepts and performance theory. In psychological management of individual performance. Https://doi.org/10.1002/0470013419.ch1

Subagyo, u., miyasto, \& idris. (2014). Analisis pengaruh budaya organisasi, kompetensi dan komitmen organisasi terhadap kinerja pegawai yang dimediasi oleh motivasi kerja. Jurnal bisnis strategi, 23(1), 138-148.

Sugiyono. (2014). Teknik pengumpulan data. In metode penelitian kuantitatif, kualitatif dan rEd. Https:// doi.org/10.3354/dao02420

Sugiyono. (2015). Metode penelitian. Metode penelitian.

Sulasmi;suhermin, m. (2016). The effects of commitment, competence, work satisfaction on motivation, and performance of employees at integrated service office of east java. International journal of advanced research, 3(november), 1-2. Https://doi.org/10.1016/s0074-6142(08)60345-9

Sunyoto, d. (2016). Teori, kuisioner dan analisis data sumber daya manusia. In teori, kuisioner dan analisis data sumber daya manusia.

Suratman hadi. (2019). Pengaruh lingkungan kerja terhadap kinerja karyawan (studi pada karyawan kantor pelayanan pajak pratama malang utara). Parameter. Https:// doi.org/10.37751/parameter.v4i2.41

Suryandita, i., \& netra, i. (2016). Pengaruh budaya organisasi, kompetensi dan lingkungan kerja fisik pada kinerja pelayanan karyawan pdam kabupaten tabanan. E-jurnal manajemen universitas udayana, 5(4), 254400.

Suwaryo, j., daryanto, h. K. K., \& maulana, a. (2016). Organizational culture change and its effect on change readiness through organizational commitment. Bisnis $\mathcal{E}$ birokrasi journal, 22(1). Https:// doi.org/10.20476/jbb.v22i1.5431

Suwondo, d. I., \& sutanto, e. M. (2015). Hubungan lingkungan kerja, disiplin kerja, dan kinerja karyawan. Jurnal manajemen dan kewirausahaan (journal of management and entrepreneurship). Https:// doi.org/10.9744/jmk.17.2.145-154

Taouab, o., \& issor, z. (2019). Firm performance: definition and measurement models. European scientific journal esj. Https:// doi.org/10.19044/esj.2019.v15n1p93

Triastuti, d. A. (2019). Pengaruh lingkungan kerja, kompetensi dan iklim organisasi terhadap kinerja pegawai. Journal of management review. Https:// doi.org/10.25157/jmr.v2i2.1796 
Trisnaningsih, s. (2007). Independensi auditor dan komitmen organisasi sebagai mediasi pengaruh pemahaman. Independensi auditor dan komitmen organisasi sebagai mediasi pengaruh pemahaman good governance, gaya kepemimpinan dan budaya organisasi terhadap kinerja auditor. Https:/ / doi.org/10.1590/s0104-14282003000200006

Wahidah, s. (2019). Jurnal mirai management jurnal mirai management. 4(2), 122-136. Https:// doi.org/10.1234/mirai.v1i1.363

Wibowo. (2011). Manajemen kinerja (p. 7). Grafindo persada.

Widodo, m. S., \& wariati, a. (2016). ( studi kasus bagian sortir pt. Tiki) di sukoharjo " "effect of work discipline, organizational commitment and work environment to employee performance ( case study of sorters sector pt. Tiki) in sukoharjo "pendahuluan pentingnya kinerja karyawan j. 2(1), 105-113.

Wirotomo, (dono), \& pasaribu, (popy). (2015). Pengaruh kompetensi, pengembangan karir, pendidikan dan pelatihan (diklat) terhadap knerja pegawai direktorat jenderal perimbangan keuangan. Mix: jurnal ilmiah manajemen.

Yaşar, m. F., ünal, ö. F., \& zaim, h. (2013). Analyzing the effects of individual competencies on performance: a field study in services industries in turkey. Journal of global strategic management. Https://doi.org/10.20460/jgsm.2013715668 